\title{
Response surface method to optimize the preparation of carboxymethyl cellulose from corn peel agricultural waste
}

\author{
Pranee Rojsitthisak*, Srichalai Khunthon, Khanittha Noomun, Sarintorn Limpanart \\ Metallurgy and Materials Science Research Institute, Chulalongkorn University, Bangkok 10330 Thailand
}

*Corresponding author, e-mail: pranee.1@chula.ac.th

Received 8 May 2016

Accepted 13 Mar 2017

\begin{abstract}
Cellulose fibres were isolated from corn peel agricultural waste using $\mathrm{NaOH}$ extraction and converted to carboxymethyl cellulose (CMC) by carboxymethylation using monochloroacetic acid (MCA) in alkaline conditions. A Box-Behnken statistical design was used to evaluate the parameters (soaking time with $\mathrm{NaOH}$ solution, soaking time with MCA solution, and reaction time with MCA) affecting the degree of substitution (DS) of CMC. Optimization was carried out by using the response surface method. The optimized conditions for CMC production with a maximal DS of 0.90 were soaking with $\mathrm{NaOH}$ for $118 \mathrm{~min}$, followed by soaking with MCA for $6.5 \mathrm{~h}$, and reaction with $\mathrm{MCA}$ at $60^{\circ} \mathrm{C}$ for $84 \mathrm{~min}$. FTIR and XRD confirmed the successful carboxymethylation. This work demonstrates the feasibility of using corn peel agricultural waste as an alternative raw material for the production of CMC with high DS.
\end{abstract}

KEYWORDS: Box-Behnken statistical design, degree of substitution, carboxymethylation

\section{INTRODUCTION}

Cellulose is an abundant biological material that is extracted commercially from lignocellulosic materials in trees and other plants ${ }^{1}$. World production of cellulose is 10000-100 000 million tons per year and the product is mainly used in the textile, paper, and material industries ${ }^{2}$. To increase the versatility of cellulose for wider applications, its properties need to be improved, especially water solubility.

Carboxymethyl cellulose (CMC) is an important derivative of cellulose. CMC is soluble in water and is used in applications such as tissue engineering ${ }^{3}$, drug delivery systems ${ }^{4,5}$, and adsorption of heavy metals ${ }^{6}$ and dyes ${ }^{7}$. CMC is commonly synthesized by carboxymethylation of cellulose with monochloroacetic acid (MCA) in alkaline conditions $^{8,9}$, with the reaction starting from the conversion of cellulose to alkaline cellulose in the presence of $\mathrm{NaOH}$ and then reaction with MCA to form CMC as the sodium salt ${ }^{10}$.

The typical raw materials for CMC production are cellulosic materials such as flax short fibres $^{11}$, sugar beet ${ }^{12}$, wood, and cotton ${ }^{13}$. In recent years, with the goal of waste utilization, agricultural wastes have also been used as raw materials for CMC production. These wastes include rice straw ${ }^{8}$, papaya peel ${ }^{14}$, orange peel ${ }^{15}$, sago waste ${ }^{16}$, sugarcane bagasse $^{17}$, corn husk ${ }^{9,18}$, banana stem ${ }^{19}$, and vine stem ${ }^{20}$. However, only a few studies have examined CMC production using corn peel as a raw material and optimization of the conditions for CMC production from corn peel using statistical design has not been reported.

The response surface method (RSM) is an effective tool for optimization, since it allows evaluation of several factors simultaneously and reduces the number of experiments required compared with the traditional step-by-step approach ${ }^{21,22}$. In the current study, Box-Behnken statistical design was used as a method of RSM that is more efficient than factorial and central composite designs ${ }^{23}$. Optimization of CMC production from corn peel was carried out using RSM, with evaluation of the effects of soaking time with $\mathrm{NaOH}$, soaking time with MCA, and reaction time with MCA on the degree of substitution (DS) of CMC. The DS is defined as the average number of free hydroxyl groups in the glucose unit of cellulose that undergo carboxymethylation.

\section{MATERIALS AND METHODS}

Fresh corn peel was collected from a central canteen at Chulalongkorn University, cut into lengths of $5 \mathrm{~cm}$, and dried by sunlight before use. MCA was purchased from Acros Organics (Geel, Belgium). $\mathrm{NaOH}$, hydrogen peroxide, ethanol and acetic acid were purchased from Carlo Erba (Rodano, Italy). All chemicals were of analytical grade and were used as 
received.

\section{Cellulose extraction from corn peel}

The 5-cm dried corn peel pieces were treated with $3 \%(\mathrm{w} / \mathrm{v}) \mathrm{NaOH}$ solution at a liquid/material ratio of $20: 1$ (v:w) at $90-100^{\circ} \mathrm{C}$ for $2 \mathrm{~h}$, as described by dos Santos et $\mathrm{al}^{24}$ with some modifications. The cellulose slurry was then filtered and washed with distilled water several times before drying it in a hot air oven at $80^{\circ} \mathrm{C}$. The obtained cellulose fibres were bleached with $0.7 \%(\mathrm{w} / \mathrm{v})$ hydrogen peroxide solution in a liquid/material ratio of $15: 1(\mathrm{v}: \mathrm{w})$ under alkaline conditions at $80-90^{\circ} \mathrm{C}$ for $90 \mathrm{~min}$. After cooling, the bleached cellulose fibres were washed with distilled water until neutral $\mathrm{pH}$ and dried in an oven at $80^{\circ} \mathrm{C}$.

\section{Preparation of CMC}

Bleached cellulose fibres $(5 \mathrm{~g})$ were suspended in $100 \mathrm{ml}$ of $95 \%(\mathrm{v} / \mathrm{v})$ ethanol, followed by addition of $10 \mathrm{ml}$ of $45 \%(\mathrm{w} / \mathrm{v}) \mathrm{NaOH}$ solution under continuous stirring at $750 \mathrm{rpm}$ at room temperature for 30,60 , or $120 \mathrm{~min}$. MCA ( $5 \mathrm{~g}$ ) was then added to the fibre slurry under continuous stirring for 3,6 , or $18 \mathrm{~h}$ at room temperature. The slurry was incubated in a water bath at $60^{\circ} \mathrm{C}$ for 30,60 , or $120 \mathrm{~min}$, and cooled before neutralization with glacial acetic acid. The obtained CMC slurry was filtered and purified by Soxhlet extraction with $500 \mathrm{ml}$ of $80 \%(\mathrm{v} / \mathrm{v})$ ethanol for $4 \mathrm{~h}$. Finally, the CMC product was dried in a hot air oven at $80^{\circ} \mathrm{C}$ and ground.

\section{Experimental design}

A polynomial model for optimization of CMC production was constructed using Box-Behnken statistical design. Data were analysed using DESIGNEXPERT 7.1 (Stat-Ease Inc., USA). The independent variables (factors) of soaking time with $\mathrm{NaOH}\left(X_{1}\right)$, soaking time with MCA $\left(X_{2}\right)$, and reaction time with MCA $\left(X_{3}\right)$ were used at 3 levels $(-1,0,+1)$ (Table 1$)$. The dependent variable (response) was the DS $(Y)$. Each experiment was performed in triplicate.

Table 1 Factors at various levels with the maximized degree of substitution as response $(Y)$.

\begin{tabular}{lccc}
\hline Factors & \multicolumn{3}{c}{ Level } \\
\cline { 2 - 4 } & Low $(-1)$ & Medium (0) & High (+1) \\
\hline$X_{1}$ (min) & 30 & 60 & 120 \\
$X_{2}$ (h) & 3 & 6 & 18 \\
$X_{3}$ (min) & 30 & 60 & 120 \\
\hline
\end{tabular}

The mathematical relationship of the response $(Y)$ and the factors $\left(X_{i}\right)$ was modelled by a secondorder polynomial function:

$$
\begin{aligned}
Y=b_{0}+b_{1} X_{1}+b_{2} X_{2} & +b_{3} X_{3} \\
+ & b_{12} X_{1} X_{2}+ \\
& b_{13} X_{1} X_{3}+b_{23} X_{2} X_{3} \\
& +b_{11} X_{1}^{2}+b_{22} X_{2}^{2}+b_{33} X_{3}^{2},
\end{aligned}
$$

where $Y$ is the measured response (DS); $b_{0}$ is the intercept; $b_{1}$ to $b_{33}$ are regression coefficients computed from observed experimental values of $Y ; X_{1}$, $X_{2}$, and $X_{3}$ are coded values of the factors, and $X_{i} X_{j}$ and $X_{i}^{2}(i, j=1,2$, and 3$)$ are interaction and quadratic terms, respectively.

Data analysis using the regression model and plotting of response surface graphs was performed in DESIGN-EXPERT. ANOVA with an $F$-test was used to evaluate the effect of each factor on the response, with $p<0.05$ considered significant. The qualitative fitness of the polynomial equation was evaluated using multiple correlation coefficients $\left(R^{2}\right)$ and adjusted $R^{2}$. Then 3D surface plots were used to show the relationship and interaction between the factors and the response. Numerical experimental regions were used to find the optimal formulation using the constraint that DS should reach a maximal level. Finally, the optimized formulation was prepared and the experimental result was compared with the predicted value obtained from the equation to evaluate the precision of the model.

\section{Characterization of cellulose fibres and CMC}

Lignin content, cellulose content in various forms, and DS of CMC were analysed based on TAPPI T 222 om-22, TAPPI T $203 \mathrm{~cm}-99$, and ASTM D 1439-03, respectively. Functional groups were identified using Fourier transform infrared spectrometry (FTIR, spectrum 400; PerkinElmer, SpectrumOne, USA) in transmittance mode at $4000-400 \mathrm{~cm}^{-1}$, with a scan number of 16 times/sample and resolution of $4 \mathrm{~cm}^{-1}$. Samples were also subjected to wide-angle X-ray diffraction (XRD, PW 3710; Philips, Netherlands), using a detector operating at a current of $30 \mathrm{~mA}$ and a voltage of $40 \mathrm{kV}$, with $\mathrm{Cu} \mathrm{K}_{\alpha}$ radiation $(1.54 \AA)$ and a scanning speed of $0.2^{\circ} 2 \theta$ /step at room temperature.

\section{RESULTS AND DISCUSSION \\ Preparation of cellulose from corn peel}

Corn peel was used as raw material because of its high $\alpha$-cellulose content of about 35\% (Table 2). The quality of the cellulose fibres mainly depends 
Table 2 Chemical compositions of corn peel and prepared cellulose fibres.

\begin{tabular}{lcc}
\hline Composition & Corn peel & Cellulose fibres \\
\hline Lignin (\%) & 5.8 & no data \\
$\alpha$-Cellulose (\%) & 34.7 & 70.6 \\
$\beta$-Cellulose (\%) & 12.0 & 24.9 \\
$\gamma$-Cellulose (\%) & 24.0 & 4.5 \\
Others (\%) & 23.5 & no data \\
\hline
\end{tabular}

on the $\mathrm{NaOH}$ concentration and reaction temperature ${ }^{25}$; hence corn peel was treated with $3 \%(\mathrm{w} / \mathrm{v})$ $\mathrm{NaOH}$ at $90-100^{\circ} \mathrm{C}$ for $2 \mathrm{~h}^{24}$. Water pollution during bleaching is also a concern; hence hydrogen peroxide was used instead of chlorine. After pulping, the $\alpha$-cellulose content increased to $71 \%$, whereas hemicelluloses ( $\beta$ - and $\gamma$-celluloses) decreased from $36 \%$ to $29 \%$ (Table 2 ).

\section{Preparation of CMC}

Preparation of CMC involved an initial stage in which cellulose fibres were treated with $\mathrm{NaOH}$ in the presence of ethanol, which functions as a swelling agent to enhance penetration of $\mathrm{NaOH}$ into the cellulose structure, followed by a second stage, in which the resulting alkaline cellulose was reacted with MCA to form CMC as a sodium salt ${ }^{24}$. Soaking time with $\mathrm{NaOH}$, soaking time with MCA, and reaction time with MCA could affect the DS of CMC. This is an important characteristic of CMC that indicates the number of substituted MCAs per glucose unit. Hivechi et $\mathrm{al}^{25}$. showed that the solubility of CMC increases with an increase in DS. Hence we chose DS as the criterion for optimal CMC synthesis.

The results in Table 3 show that the DS was in the range of 0.51-0.82 and the main factor affecting DS was the reaction time with MCA. An increase in reaction time with MCA up to $120 \mathrm{~min}$ resulted in an increase in DS, regardless of the soaking times with $\mathrm{NaOH}$ and MCA. A similar observation was made for sago waste ${ }^{26}$. This result is probably due to the prolongation of carboxymethylation allowing more time for MCA to react with the cellulose fibres, with a higher resulting DS.

\section{Fitting data to a model}

To select the best model for fitting the data, an $F$-value from ANOVA was used. Singare et $\mathrm{al}^{27}$ showed that factors with $p<0.05$ (prob $>F$-value) have a significant effect on the response. $R^{2}$ represents the percentage of data that is closest to the best fit line, and thus an $R^{2}$ close to 1 indicates a
Table 3 Variables and response in Box-Behnken design for CMC production.

\begin{tabular}{lrrrc}
\hline Run no. & \multicolumn{3}{c}{ Independent variables } & Response \\
\cline { 2 - 4 } & $X_{1}(\mathrm{~min})$ & $X_{2}(\mathrm{~h})$ & $X_{3}(\mathrm{~min})$ & $Y_{1}$ \\
\hline 1 & 30 & 3 & 60 & $0.79 \pm 0.01$ \\
2 & 120 & 3 & 60 & $0.71 \pm 0.01$ \\
3 & 30 & 18 & 60 & $0.79 \pm 0.20$ \\
4 & 120 & 18 & 60 & $0.74 \pm 0.12$ \\
5 & 30 & 6 & 30 & $0.58 \pm 0.01$ \\
6 & 120 & 6 & 30 & $0.62 \pm 0.03$ \\
7 & 30 & 6 & 120 & $0.77 \pm 0.03$ \\
8 & 120 & 6 & 120 & $0.82 \pm 0.08$ \\
9 & 60 & 3 & 30 & $0.51 \pm 0.01$ \\
10 & 60 & 18 & 30 & $0.59 \pm 0.04$ \\
11 & 60 & 3 & 120 & $0.80 \pm 0.01$ \\
12 & 60 & 18 & 120 & $0.70 \pm 0.02$ \\
$13^{\mathrm{a}}$ & 60 & 6 & 60 & $0.75 \pm 0.03$ \\
$14^{\mathrm{a}}$ & 60 & 6 & 60 & $0.78 \pm 0.03$ \\
$15^{\mathrm{a}}$ & 60 & 6 & 60 & $0.82 \pm 0.02$ \\
\hline
\end{tabular}

${ }^{\text {a }}$ Indicates the centre point of the design.

model that fits the data well. The results showed that a full quadratic polynomial fitted the data and that the lack of fit $F$-value of 0.13 was not significant in this response $(p>0.05)$ (Table 4). Multiple regression analysis showed that all linear, squared and interaction coefficients of the factors, including soaking time with $\mathrm{NaOH}$ and reaction time with MCA, were significant $(p<0.05)$ when DS was used as a response. The derived equation that fitted the data was

$$
\begin{array}{r}
Y=0.78+0.045 X_{1}-0.016 X_{2}+0.11 X_{3} \\
+0.088 X_{1} X_{2}-0.022 X_{1} X_{3}-0.04 X_{2} X_{3} \\
-0.018 X_{1}^{2}-0.064 X_{2}^{2}+0.084 X_{3}^{2},
\end{array}
$$

where $Y$ is the DS, $X_{1}$ is the soaking time with $\mathrm{NaOH}, X_{2}$ is the soaking time with MCA, and $X_{3}$ is the reaction time with MCA.

In the polynomial (1), a positive sign indicates a synergistic effect and a negative sign indicates an antagonistic effect ${ }^{26}$. The model was significant $(F=37.40, p<0.0005)$ (Table 4$)$. The values of $R^{2}=0.99$, predicted $R^{2}=0.93$, and adjusted $R^{2}=$ 0.96 were in reasonable agreement. The signal-tonoise ratio was satisfactory since the precision ratio of 20.008 is above 4 (data not shown). Thus this model could be used to navigate the design space.

From the polynomial (1), it is clear that factor $X_{3}$, the reaction time with MCA, affected DS of the CMC positively. This means that DS increased as the reaction time with MCA increased. This is 
Table 4 ANOVA for DS.

\begin{tabular}{lccccc}
\hline Source & Sum of squares & $\mathrm{df}$ & Mean square & $F$-value & $p$ value (prob $>F$-value) \\
\hline Model & 0.20 & 9 & 0.022 & 37.40 & 0.0005 \\
$X_{1}$ & 0.016 & 1 & 0.016 & 27.54 & 0.0033 \\
$X_{2}$ & 0.002113 & 1 & 0.002113 & 3.59 & 0.1166 \\
$X_{3}$ & 0.099 & 1 & 0.099 & 168.29 & 0.0001 \\
$X_{1} X_{2}$ & 0.031 & 1 & 0.031 & 52.05 & 0.0008 \\
$X_{1} X_{3}$ & 0.002025 & 1 & 0.002025 & 3.44 & 0.1227 \\
$X_{2} X_{3}$ & 0.0064 & 1 & 0.0064 & 10.88 & 0.0215 \\
$X_{1}^{2}$ & 0.001241 & 1 & 0.001241 & 2.11 & 0.0038 \\
$X_{2}^{2}$ & 0.015 & 1 & 0.015 & 25.84 & 0.0011 \\
$X_{3}^{2}$ & 0.026 & 1 & 0.026 & 44.46 & 0.9351 \\
Residual & 0.002942 & 5 & 0.000588 & & 0.0005 \\
Lack of fit & 0.00475 & 3 & 0.000158 & 0.13 & 0.0033 \\
Pure error & 0.002467 & 2 & 0.001233 & & 37.40 \\
Cor total & 0.20 & 14 & 0.022 & & \\
$R^{2}$ & 0.9854 & & & & \\
Adjusted $R^{2}$ & 0.9590 & & & & \\
Predicted $R^{2}$ & 0.9346 & & & & \\
\hline
\end{tabular}

probably because MCA has more time to react with cellulose fibres, resulting in greater substitution of the hydroxyl group. Factor $X_{1}$, the soaking time with $\mathrm{NaOH}$, also had a significant effect, with a slightly positive value. An increased soaking time with $\mathrm{NaOH}$ produces more swelling of cellulose fibres and causes more alkaline saturation, which allows MCA to react with the alkaline cellulose more easily. However, the soaking time with MCA $\left(X_{2}\right)$ at room temperature did not have a significant effect $(p>$ 0.05 ) on DS. This may be because the temperature was not high enough for the reaction, since dos Santos et $\mathrm{al}^{24}$. showed that the temperature for carboxymethylation did affect the DS of CMC.

The 3D response surface plots of the effects of factors on the response $(Y)$ are illustrated in Fig. 1. In each plot, the interaction of two variables was investigated simultaneously while the third factor was kept constant. The response surface curve in Fig. 1a shows an increase in DS with an increase of soaking time with $\mathrm{NaOH}$. That is, quadratic coefficients of soaking time with $\mathrm{NaOH}$ in the model were significant, whereas the soaking time with MCA did not have a significant effect on DS. However, the interaction effect of soaking time with $\mathrm{NaOH}$ and soaking time with MCA was significant $(p<0.05)$. In Fig. 1b, the minimal DS occurs at low soaking time with $\mathrm{NaOH}$ and low reaction time with MCA. Increasing the reaction time with MCA from 30$120 \mathrm{~min}$ led to an increase in DS from 0.58-0.77. Fig. 1c also shows that DS increased as a function of the reaction time with MCA, but did not depend on the soaking time with MCA.

\section{Optimization and validation of the model}

The optimal conditions for CMC production with maximal DS were analysed by DESIGN-EXPERT based on the desirability coefficient close to 1 . The results indicated that a soaking time with $\mathrm{NaOH}$ of 118 min, a soaking time with MCA of $6.5 \mathrm{~h}$, and a reaction time with MCA of $84 \mathrm{~min}$ were optimal. The predicted DS was about 0.90. Comparison of the experimental DS $(0.93 \pm 0.03)$ with the predicted value indicated only a slight difference, with a prediction error of 3\%. Hence the Box-Behnken statistical design and optimization method used in the study were suitable to prepare CMC with a maximal DS. In addition, the other characteristics of CMC produced from the optimal condition could reach the specification of CMC in the market (Table 5).

Table 5 Characteristics of CMC produced from the optimal condition and commercial CMC.

\begin{tabular}{lll}
\hline Characteristics & $\begin{array}{l}\text { Optimal } \\
\text { condition }\end{array}$ & $\begin{array}{l}\text { Commercial } \\
\text { CMC }\end{array}$ \\
\hline Appearance: form \\
colour & $\begin{array}{l}\text { Powder } \\
\text { White }\end{array}$ & $\begin{array}{l}\text { Powder } \\
\text { White to } \\
\text { light yellow }\end{array}$ \\
& & - \\
Yield (\%) & $81.9 \pm 1.1$ & $-5 \%$ \\
Moisture (\%) & $7.54 \pm 0.07$ & $\leqslant 8 \%$ \\
DS & $0.93 \pm 0.03$ & $0.6-1.45$ \\
Sodium (ICP) & $11.3 \pm 0.7$ & $10.5-12.0$ \\
Molecular weight (Da) & $5.25 \times 10^{5}$ & $(3.0-10) \times 10^{5}$ \\
Viscosity (cps) $^{\dagger}$ & $275 \pm 36$ & $25-850$ \\
\hline
\end{tabular}

${ }^{\dagger}$ at $2 \%$ in water, $25^{\circ} \mathrm{C}$. 

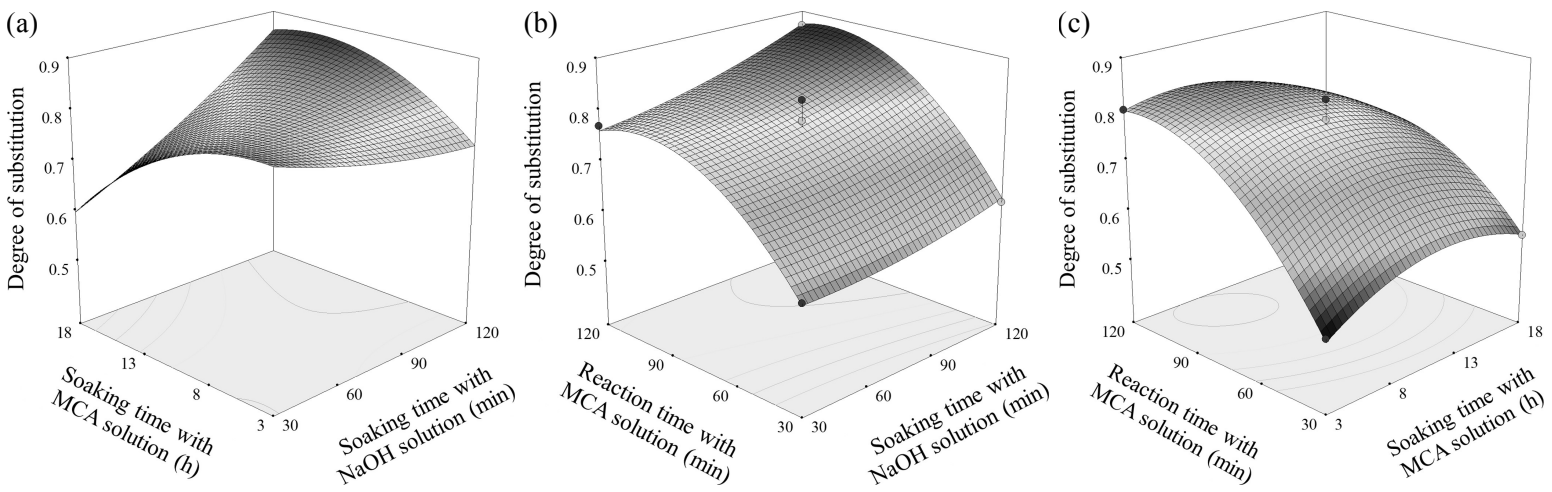

Fig. 1 3D response surface plots showing the effect of (a) soaking time with $\mathrm{NaOH}\left(X_{1}\right)$ and soaking time with MCA $\left(X_{2}\right)$; (b) soaking time with $\mathrm{NaOH}\left(X_{1}\right)$ and reaction time with MCA $\left(X_{3}\right)$; and (c) soaking time with MCA $\left(X_{2}\right)$ and reaction time with MCA $\left(X_{3}\right)$ on degree of substitution $(Y)$.

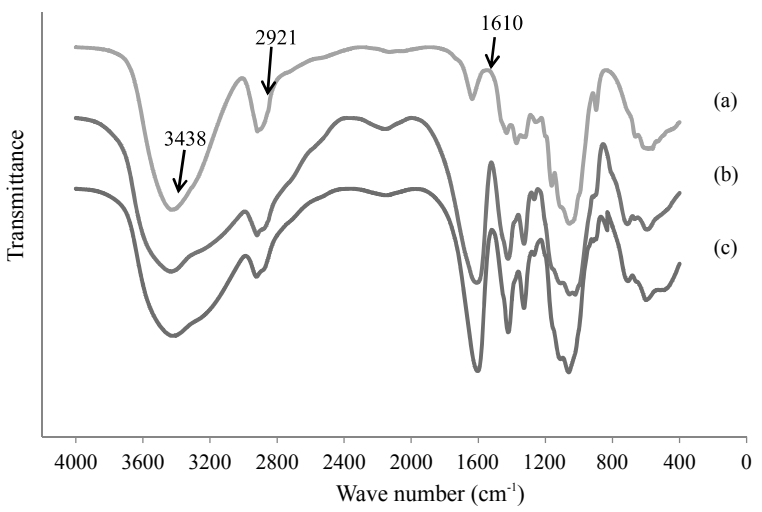

Fig. 2 FTIR spectra of (a) cellulose fibres extracted from corn peel, (b) standard CMC, and (c) CMC obtained under the optimized conditions.

\section{Characterization of the optimized formulation}

The IR spectrum of CMC produced using the optimized conditions (Fig. 2c) is similar to that of standard commercial CMC (Fig. 2b). However, some peaks of commercial CMC are broader compared to those in the spectrum of cellulose fibres extracted from corn peel (Fig. 2a). A broad peak in the region of $3000-3600 \mathrm{~cm}^{-1}$ represents the $\mathrm{OH}$ stretching with intra- and intermolecular hydrogen bonds, suggesting that the $\mathrm{OH}$ groups at $\mathrm{C}_{2}, \mathrm{C}_{3}$, and $\mathrm{C}_{6}$ on the pyranose ring in $\mathrm{CMC}$ were substituted by $\mathrm{CH}_{2} \mathrm{COO}^{-28,29}$. In addition, the $\mathrm{OH}$ peak near $3500 \mathrm{~cm}^{-1}$ and $\mathrm{CH}$ peak at $2900 \mathrm{~cm}^{-1}$ decreased and the peak for $-\mathrm{COO}-$ at $1600 \mathrm{~cm}^{-1}$ was stronger in the spectrum of commercial CMC. The peaks at $1000-1460 \mathrm{~cm}^{-1}$ shows $\mathrm{C}-\mathrm{O}$ and $\mathrm{CH}$ vibration bands of the pyranose ring, the skeletal structure of cellulose ${ }^{29,30}$. Except for additional peaks at

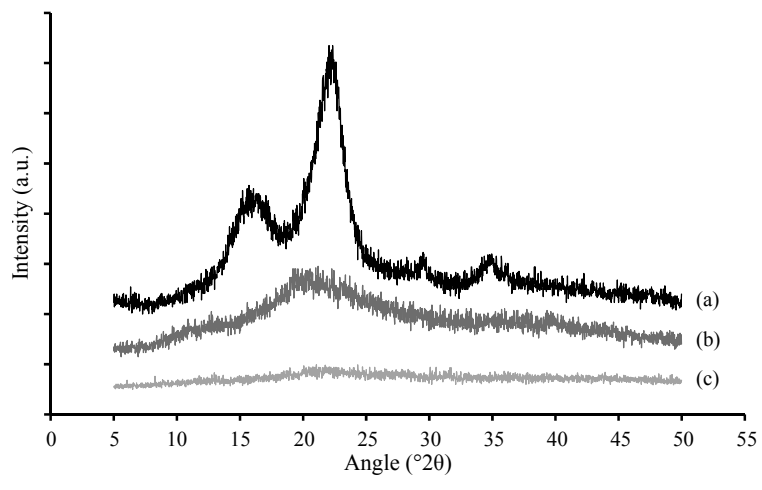

Fig. 3 X-ray diffractograms of (a) cellulose fibres extracted from corn peel, (b) standard CMC, and (c) CMC obtained under the optimized conditions.

2880 and $2921 \mathrm{~cm}^{-1}$, CH stretching bands were unchanged. This indicates that the $\mathrm{CH}$ groups of the pyranose ring did not react with MCA and that esterification mainly occurred at the $\mathrm{OH}$ at the $\mathrm{C}_{6}$ position.

Fig. 3 shows the XRD pattern of CMC obtained under the optimized conditions, compared with those for standard CMC and cellulose fibres extracted from corn peel. The crystal structure of cellulose fibres extracted from corn peel decreased after carboxymethylation. Similar results were observed by de Santos et $\mathrm{al}^{24}$, Chen et $\mathrm{al}^{31}$, and Terinte et $\mathrm{al}^{32}$. The diffraction peak of cellulose fibres at $16^{\circ}$ $2 \theta$ and $22^{\circ} 2 \theta$ decreased and disappeared after the reaction with MCA and transformed into amorphous phase. This might be due to the substitution of $\mathrm{OH}$ groups in cellulose with $\mathrm{CH}_{2} \mathrm{COO}^{-}$groups. 


\section{CONCLUSIONS}

Response surface method was successfully applied for optimization of preparation of CMC from corn peel. DS was affected by the reaction time with MCA and the soaking time with $\mathrm{NaOH}$. The optimal conditions for preparation of CMC using RSM method were soaking with $\mathrm{NaOH}$ for 118 min, followed by soaking with MCA for $6.5 \mathrm{~h}$, and reaction with MCA at $60^{\circ} \mathrm{C}$ for $84 \mathrm{~min}$, which produced a DS of 0.90 .

Acknowledgements: The authors express their sincere thanks to the Ratchadapisek Sompoch Endowment Fund (2013) of Chulalongkorn University (CU-56-802-FC) for providing research funds.

\section{REFERENCES}

1. Ummartyotin S, Manuspiya H (2015) A critical review on cellulose: from fundamental to an approach on sensor technology. Renew Sustain Energ Rev 41, 402-12.

2. Azizi Samir MAS, Alloin F, Dufresne A (2005) Review of recent research into cellulosic whiskers, their properties and their application in nanocomposite field. Biomacromolecules 6, 612-26.

3. Khan F, Ahmad SR (2013) Polysaccharides and their derivatives for versatile tissue engineering application. Macromol Biosci 13, 395-421.

4. Kim MS, Park SJ, Gu BK, Kim C-H (2012) Ionically crosslinked alginate-carboxymethyl cellulose beads for the delivery of protein therapeutics. Appl Surf Sci 262, 28-33.

5. Zhou HY, Cao PP, Li JB, Zhang FL, Ding PP (2015) Preparation and release kinetics of carboxymethyl chitosan/cellulose acetate microspheres as drug delivery system. J Appl Polymer Sci 132, 26.

6. Wei W, Kim S, Song M-H, Bediako JK, Yun Y-S (2015) Carboxymethyl cellulose fiber as a fast binding and biodegradable adsorbent of heavy metals. J Taiwan Inst Chem Eng 57, 104-10.

7. Zhang G, Yi L, Deng H, Sun P (2014) Dyes adsorption using a synthetic carboxymethyl cellulose-acrylic acid adsorbent. $J$ Environ Sci 26, 1203-11.

8. Abdel-Mohdy FA, Abdel-Halim ES, Abu-Ayana YM, El-Sawy SM (2009) Rice straw as a new resource for some beneficial uses. Carbohydr Polymer 75, 44-51.

9. Yeasmin MS, Mondal MIH (2015) Synthesis of highly substituted carboxymethyl cellulose depending on cellulose particle size. Int J Biol Macromol 80, 725-31.

10. Joshi G, Naithani S, Varshney VK, Bisht SS, Rana V, Gupta PK (2015) Synthesis and characterization of carboxymethyl cellulose from office waste paper: a greener approach towards waste management. Waste Manag 38, 33-40.

11. Kutsenko LI, Bochek AM, Vlasova EN, Volchek BZ (2005) Synthesis of carboxymethyl cellulose based on short fibers and lignified part of flax pedicels (Boon). Russ J Appl Chem 78, 2014-8.

12. Toğrul H, Arslan N (2003) Production of carboxymethyl cellulose from sugar beet pulp cellulose and rheological behaviour of carboxymethyl cellulose. Carbohydr Polymer 54, 73-82.

13. Singh RK, Singh AK (2013) Optimization of reaction conditions for preparing carboxymethyl cellulose from corn cobic agricultural waste. Waste Biomass Valoriz 4, 129-37.

14. Rachtanapun P (2009) Blended films of carboxymethyl cellulose from papaya peel (CMCp) and corn starch. Kasetsart J (Nat Sci) 43, 259-66.

15. Yaşar F, Toğrul H, Arslan N (2007) Flow properties of cellulose and carboxymethyl cellulose from orange peel. J Food Eng 81, 187-99.

16. Pushpamalar V, Langford SJ, Ahmad M, Lim YY (2006) Optimization of reaction conditions for preparing carboxymethyl cellulose from sago waste. Carbohydr Polymer 64, 312-8.

17. Viera RGP, Filho GR, de Assunção RMN, Meireles C, da S, Vieira JG, de Oliveira GS (2007) Synthesis and characterization of methylcellulose from sugar cane bagasse cellulose. Carbohydr Polymer 67, 182-9.

18. Mondal MIH, Yeasmin MS, Rahman MS (2015) Preparation of food grade carboxymethyl cellulose from corn husk agrowaste. Int J Biol Macromol 79, 144-50.

19. Adinugraha MP, Marseno DW, Haryadi (2005) Synthesis and characterization of sodium carboxymethyl cellulose from cavendish banana pseudo stem (Musa cavendishii Lambert). Carbohydr Polymer 62, 164-9.

20. Mansouri S, Khiari R, Bettaieb F, El-Gendy AA, Mhenni F (2015) Synthesis and characterization of carboxymethyl cellulose from tunisian vine stem: study of water absorption and retention capacities. J Polymer Environ 23, 190-8.

21. Bhunchu S, Rojsitthisak P, Rojsitthisak P (2015) Response surface methodology to optimize the preparation of chitosan/alginate nanoparticles containing curcumin diethyl disuccinate. Adv Mater Res 1119, 398-402.

22. Motwani SK, Chopra S, Talegaonkar S, Kohli K, Ahmad FJ, Khor RK (2008) Chitosan-sodium alginate nanoparticles as submicroscopic reservoirs for ocular delivery: formulation, optimization and in vitro characterization. Eur J Pharm Biopharm 68, 513-25.

23. Boonyasirisri P, Nimmannit U, Rojsitthisak P, Bhunchu S, Rojsitthisak P (2015) Optimization of curcuminoid-loaded PLGA nanoparticles using Box-Behnken statistical design. J Nano Res 33, 60-71.

24. Martins dos Santos D, Bukzem AL, Ascheri DPR, Signini R, Aquino GLB (2015) Microwave-assisted carboxymethylation of cellulose extracted from brewer's spent grain. Carbohydr Polymer 131, 125-33.

25. Hivechi A, Bahrami SH, Arami M, Karimi A (2015) 
Ultrasonic mediated production of carboxymethyl cellulose: optimization of conditions using response surface methodology. Carbohydr Polymer 134, 278-84.

26. Ibrahim HM, Ismail HR, Lila AEA (2012) Formulation and optimization of ocular poly-D,L-lactic acid nano drug delivery system of amphotericin-B using Box-Behnken design. Int $J$ Pharm Pharmaceut Sci 4, 342-9.

27. Singare DS, Marella S, Gowthamrajan K, Kulkarni GT, Vooturi R, Rao PS (2010) Optimization of formulation and process variable of nanosuspension: an industrial perspective. Int J Pharm 402, 213-20.

28. Zhbankov RG, Firsov SP, Buslov DK, Nikonenko NA, Marchewka MK, Ratajczak H (2002) Structural physic-chemistry of cellulose macromolecules: vibrational spectra and structure of Cellulose. J Mol Struct 614, 117-25.

29. Ismail NM, Bono A, Valintinus ACR, Nilus S, Chng LM (2010) Optimization of reaction conditions for reparing carboxymethyl cellulose. J Appl Sci 10, 2530-6.

30. Colthup NB, Daly LH, Wiberley SE (1990) Introduction to Infrared and Raman Spectroscopy, 3rd edn, Academic Press, Inc.

31. Chen Q, Wang Q, Mitsumura N, Niida H (2013) Improved cellulose by ionic liquid mixture with solid acid catalysis and its application in polyethylene glycol. Mater Sci Appl 4, 839-45.

32. Terinte N, Ibbett R, Schuster KC (2011) Overview on native cellulose and microcrystalline cellulose I structure studied by X-ray diffraction (WAXD): comparison between measurement techniques. Lenzing Ber 89, 118-31. 